\title{
IgG antibodies to Aspergillus fumigatus in cystic fibrosis: a laboratory correlate of disease activity
}

\author{
K D FORSYTH, ${ }^{*}$ A W HOHMANN, $\dagger$ A J MARTIN, $\ddagger$ AND J BRADLEY $\uparrow$ \\ Departments of *Paediatrics and \Immunology, Flinders University of South Australia, †Flinders Medical \\ Centre, and $¥$ Adelaide Children’s Hospital, Adelaide, South Australia
}

SUMmaRY Serum was collected from 50 patients with cystic fibrosis, and IgG antibodies to Aspergillus fumigatus were measured by enzyme linked immunosorbent assay (ELISA). In addition, total IgE and Aspergillus specific IgE antibodies were measured in 41 of the 50. A close association was found between pulmonary function and clinical state, and IgG antibodies to Aspergillus. There was no association between pulmonary function or clinical state and IgE antibodies.

It is postulated that in patients with cystic fibrosis, Aspergillus fumigatus may contribute to deterioration in pulmonary function by local pathogenicity, or by hypersensitivity mechanisms mediated by $\mathrm{IgG}$.

Pulmonary disease is the major cause of morbidity and mortality among patients with cystic fibrosis. Little is known about pulmonary mucosal defence mechanisms, even in the healthy adult. IgG is known to be the predominant pulmonary immunoglobulin in both adults ${ }^{1}$ and children, ${ }^{2}$ and $\operatorname{IgA}$ is more important in the upper airway. IgG is an efficient fixer of complement, so there is the potential in the lower respiratory tract for IgG hypersensitivity mechanisms to occur if there is immune dysregulation. The most important cause of progressive pulmonary disease in cystic fibrosis is likely to be chronic infection with Pseudomonas aeruginosa. ${ }^{3}$ Two studies, however, have shown that children with cystic fibrosis and low concentrations of serum IgG had better lung function and general health than age matched children with cystic fibrosis and normal IgG concentrations. ${ }^{4-5}$ Overall, patients with cystic fibrosis have higher serum IgG and IgM concentrations than control subjects. ${ }^{6}$ It has also been shown that high titres of precipitating antibodies to $P$ aeruginosa in patients with cystic fibrosis may be harmful rather than protective. ${ }^{7-8}$ Circulating immune complexes are common in cystic fibrosis, and are associated with acute respiratory exacerbations and deteriorating pulmonary function. ${ }^{9}$ These features suggest that hypersensitivity mechanisms and increased inflammatory activity may participate in the pulmonary damage. Indeed the results of a trial of prednisolone given on alternate days to patients with cystic fibrosis suggested that there was an appreciable delay in deterioration of lung function tests and fewer hospital admissions in the group treated with prednisolone. ${ }^{10}$

The frequency with which Aspergillus precipitins are detected in patients with cystic fibrosis varies from $30 \%$ to $60 \%,{ }^{11-12}$ and their number often parallels the severity of pulmonary disease. ${ }^{13}$ $A$ fumigatus is a ubiquitous fungus, and all lungs are constantly exposed to it. Allergic aspergillosis has been reported in up to $11 \%$ of patients with cystic fibrosis, ${ }^{14}$ but is rare in normal subjects. This suggests that patients with cystic fibrosis have an abnormal response to Aspergillus, and that there may be important abnormalities in mucosal regulation and defence in patients with cystic fibrosis. Unfortunately precipitation in gels is an insensitive, albeit specific, method for the detection of circulating Aspergillus antibody. In addition, it is qualitative, not quantitative.

Our aim was to characterise more fully the response to Aspergillus in patients with cystic fibrosis, and to relate the findings to their general health and pulmonary function. An ELISA for the detection of serum IgG antibodies to $A$ fumigatus that had been developed in our laboratory was therefore applied to the serum of patients with cystic fibrosis. This ELISA gives quantitative results with high sensitivity. 


\section{Patients and methods}

Serum for assay of IgG antibody to $A$ fumigatus was collected from 50 patients with cystic fibrosis as part of their routine annual blood monitoring. A few of the patients had serum collected during an admission to hospital because of exacerbation of their pulmonary disease. Their ages ranged from 2.5 to 29 years. Forty one patients also had total IgE and Aspergillus specific IgE measured. As sputum culture for Aspergillus is somewhat unreliable, it was not performed. Serum was also collected from 40 age matched patients with mild, episodic asthma to serve as controls. There were insufficient age matched patients with bronchiectasis who did not have cystic fibrosis to act as controls.

For the Aspergillus IgG ELISA, the Aspergillus antigen was prepared from a commercially available supply (Aspergillus somatic antigen, Mercia Brocades). The Aspergillus antigen was diluted to $25 \mu \mathrm{g} / \mathrm{ml}$ in sodium carbonate buffer, $\mathrm{pH} 9 \cdot 6$. Fifty microlitres of the diluted antigen was added to a 96 well, round bottomed, polystyrene, microtitre plate and left at $4^{\circ} \mathrm{C}$ overnight. There were eight dilutions of each serum starting at $1 / 15$ and diluting three fold from then on-that is, $1 / 45,1 / 135,1 / 405$, and so on. These dilutions were performed in triplicate in phosphate buffered saline (PBS) containing $0.05 \%$ Tween 20 and $0.25 \%$ bovine serum albumin (PBST-BSA). This was added to the antigen coated plates and incubated for one hour at $37^{\circ} \mathrm{C}$, followed by two hours at $4^{\circ} \mathrm{C}$. Plates were then washed five times with PBS-T, and $100 \mu \mathrm{l}$ of alkaline phosphatase labelled antihuman IgG (DAKO) added to each well and incubated for 16 hours at $4^{\circ} \mathrm{C}$. Plates were washed five times in PBS-T and $100 \mu \mathrm{l}$ of a $1 \mathrm{mg} / \mathrm{ml}$ solution of p-nitrophenyl phosphate in diethanolamine buffer, $\mathrm{pH} 9 \cdot 8$, added to each well. After 30 minutes at $37^{\circ} \mathrm{C}$ the reaction was stopped by adding edetic acid to a final concentration of 40 $\mathrm{mM}$. Absorbance was measured at $405 \mathrm{~nm}$ on an automatic ELISA plate reader (Dynatech MR600), and graphs were drawn for each serum. The serum titre was calculated by interpolation of the graphs, and expressed as the serum dilution yielding an optical density of $0 \cdot 4$. ELISA units were calculated by reference to a known positive reference included in each run. This consisted of a pool of seven high titre serum samples in aliquots stored at $-80^{\circ} \mathrm{C}$. One aliquot was removed and run with each test.

Using the result from the reference aliquot, an ELISA value was given for each sample using the following formula: titre of test serum $\times 1000 /$ titre of reference serum $=$ ELISA units. The reference samples were arbitrarily assigned a value of 1000 units, and each test sample was compared with this value. The interassay coefficient of variation for this ELISA is $23 \%$, and the intra-assay variation $10.4 \%$. Total serum IgE was measured with the Phadezym IgE PRIST, and Aspergillus specific IgE antibodies were measured with Phadezym RAST 60 (Pharmacia Diagnostics AB).

Except for seven patients who were too young, all had pulmonary function tests performed; these were done with the patient standing. Maximum expiratory flow volume curves were obtained with an OHIO 842 spirometer and the curves were displayed on a Hewlett-Packard 7041 A X-Y recorder. Forced vital capacity (FVC), forced expiratory volume in one second $\left(\mathrm{FEV}_{1}\right)$, and forced expiratory flow measured between $25 \%$ and $75 \%$ of the expired vital capacity $\left(\mathrm{FEF}_{25-75}\right)$, were derived from the curve. At least three curves were performed for each subject. The results were expressed as a percentage of expected value for height.

The general health of the patients was assessed using the Shwachman score, a four way appraisal of health covering general activity, physical examination, nutrition, and chest radiograph. ${ }^{15}$

Pearson correlation coefficients were computed from linear regression analyses. Significance was assessed by reference to standard tables.

\section{Results}

All control subjects had undetectable IgG specific antibodies to $A$ fumigatus.

Overall, $70 \%$ of the patients with cystic fibrosis had measureable IgG antibodies to Aspergillus. All patients older than 12 years had measurable IgG antibodies (fig. 1). No patient younger than 4 years had detectable antibodies. There was a progressive rise in antibody titres with increasing age $(r=0.57$, $\mathrm{p}<0 \cdot 001)$. The three patients who died from their

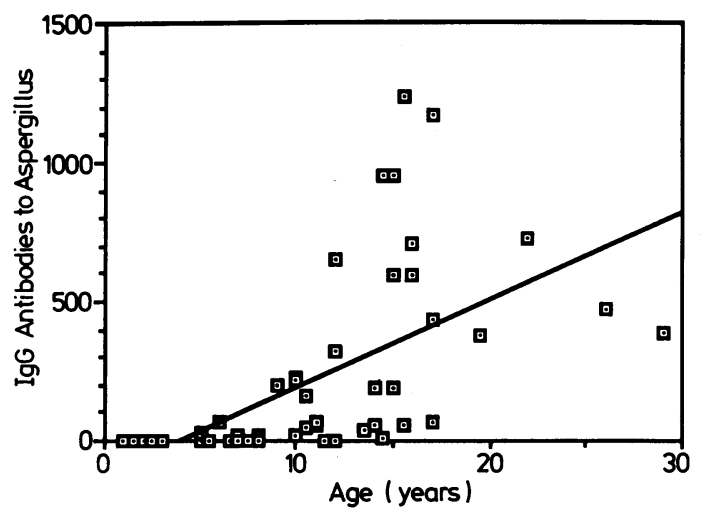

Fig 1 IgG antibodies to Aspergillus (ELISA units) and age; $r=0.57 p<0.001$. Some values are concentric. 
disease during the study had IgG antibody titres of 250, 978, and 1198 units.

There was a close correlation between the Aspergillus IgG value and the Shwachman score (fig 2). As the Shwachman score deteriorated the Aspergillus IgG value increased $(\mathrm{r}=-0.79, \mathrm{p}<0.001)$. All patients with Shwachman scores of less than 70 had detectable antibodies. There was also a close correlation between increasing Aspergillus IgG values and deteriorating pulmonary function (figs 3-5). $\mathrm{FEV}_{1}$ and $\mathrm{FEF}_{25-75}$ as \% of predicted values showed similar results $(\mathrm{r}=-0.67$ and $-0.68, \mathrm{p}<0.001)$. With increasing Aspergillus IgG values there was a fall in FVC $(\mathrm{r}=-0.61, \mathrm{p}<0.001)$. All patients with $\mathrm{FEF}_{25-75}$ less than $68 \%, \mathrm{FEV}_{1}$ less than $75 \%$, FVC less than $60 \%$ of predicted values, had detectable Aspergillus IgG antibodies.

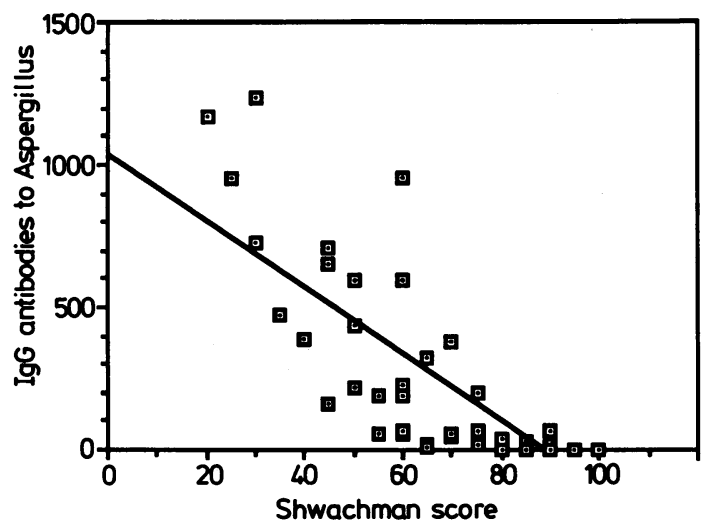

Fig 2 IgG antibodies to Aspergillus (ELISA units) and Shwachman score; $r=-0.79, p<0.001$. Some values are concentric.

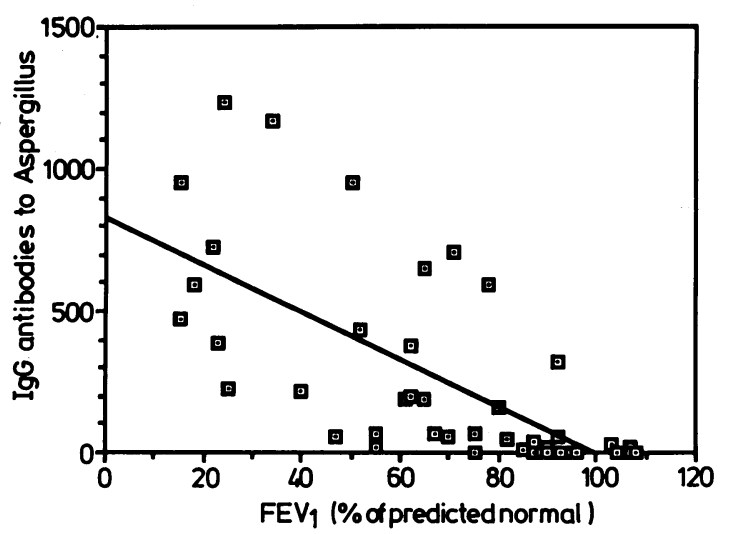

Fig 3 IgG antibodies to Aspergillus (ELISA units) and $F E V_{l} ; r=-0.68, p<0.001$. Some values are concentric.

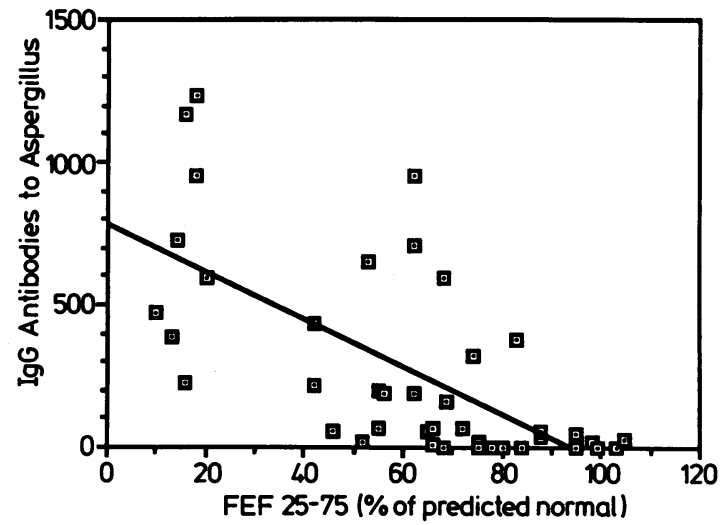

Fig 4 IgG antibodies to Aspergillus (ELISA units) and FEF 25-75. $r=-0.67, p<0.001$. Some values are concentric.

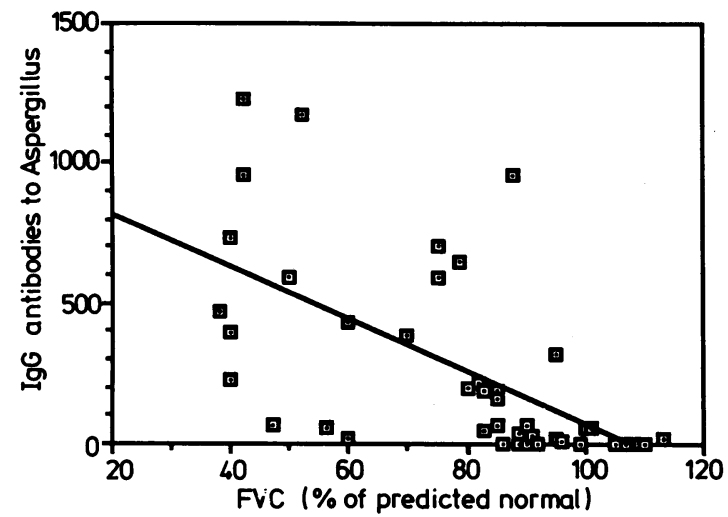

Fig 5 IgG antibodies to Aspergillus (ELISA units) and FVC. $r=-0.61, p<0 \cdot 001$. Some values are concentric.

There was no correlation between Aspergillus IgG antibody titres and either Aspergillus IgE titres or total IgE. Nine of 47 patients tested $(19 \%)$ had detectable IgE antibodies to Aspergillus, and 10 of $41(24 \%)$ had raised total IgE concentrations.

\section{Discussion}

A fumigatus is present in air, soil, animals, plants, and water. It has even been reported in $90 \%$ of commercial packages of macaroni, spaghetti, and similar pasta products. ${ }^{16}$ The isolation of Aspergillus in sputum is therefore difficult to interpret. Airborne Aspergillus can lodge on sputum as it is expectorated or during culture making the assessment of colonisation or infection difficult. Hence, serological evidence of Aspergillus is more specific. This fungus can, after inhalation, produce different 
patterns of respiratory tract infection: saprophytic bronchopulmonary aspergillosis (colonisation), aspergilloma (mycetoma or fungus ball), hypersensitivity induced aspergillosis, and invasive pulmonary aspergillosis. ${ }^{17}$

Our finding of IgG antibodies to Aspergillus in $70 \%$ of patients with cystic fibrosis is the highest reported. That the antibody titre rises with increasing age, falling Shwachman score, and falling respiratory function values, indicates the importance of the fungus in patients with cystic fibrosis. Rising Aspergillus IgG values with age indicate progressively more exposure to the fungus, or a progressively aberrant immune reponse. The high serum IgG values in those patients in a poor clinical state (low Shwachman score) presumably reflects a high antigen load presented to the systemic immune system, possibly because of inefficient removal of antigen from diseased, bronchiectatic lungs. That no child younger than 4 years had detectable antibodies might suggest that appreciable anatomical or immunological airway disease becomes established after that age.

The closest correlation with the Aspergillus IgG value was the Shwachman score, a measurement of general health. If the severity of lung disease was the measurement most influencing the development of IgG antibodies, we might have expected the correlation between the antibody titre and respiratory function results to have been closer than that between antibody titre and Shwachman score. Limitations in the ELISA or the respiratory function testing, or the influence of other aspects of pulmonary disease may have influenced this result. In addition, the degree of bronchiectasis, mucus plugging, and narrowing of small airways is variable in those dying from cystic fibrosis. ${ }^{18}$

There is evidence that high precipitating antibodies against $P$ aeruginosa may be important in exacerbating pulmonary disease through inflammatory mechanisms. ${ }^{1-y}$ We found high titres of IgG antibodies to Aspergillus, particularly in those with more severe disease. Raised IgG antibody titres in those with more severe disease may simply be due to colonisation of damaged lung. Another possibility is that the high antibody titres might lead to an increase in the amount of inflammation in diseased lungs-for example, through immune complexes and complement activation-contributing to further damage. ${ }^{9}$

Invasive aspergillosis is lethal and requires specific antifungal chemotherapy. Pulmonary invasion is said to occur because of decreased host defences, particularly in neutropenia and leukaemia, with colonisation only occurring in the presence of chronic lung disease. ${ }^{19}$ There is some evidence of decreased systemic immunity in cystic fibrosis, ${ }^{20}$ and little is known about respiratory mucosal defence. In addition, invasive pulmonary aspergillosis has been reported recently in patients who were neither immunocompromised nor neutropenic. ${ }^{21}$ We have established that there is a vigorous response to Aspergillus, particularly in those with more severe disease. It s important therefore to ensure that some degree of localised pulmonary invasion by Aspergillus is not occurring late in the course of their disease.

Hypersensitivity induced aspergillosis has been reported in $11 \%$ of patients with cystic fibrosis. ${ }^{14}$ That $19 \%$ of our patients had positive RAST scores to Aspergillus suggests that a sizeable subgroup of patients with cystic fibrosis may have abnormal immune regulation to this fungus, particularly at the respiratory mucosal surface. As there was no correlation between pulmonary function and Aspergillus specific IgE antibodies, however, it is unlikely that mechanisms mediated by $\operatorname{IgE}$ are important in most of these patients. Further studies on respiratory mucosal defence and the influence of Aspergillus on lung disease in patients with cystic fibrosis are needed. In particular, pharmacological measures aimed at reducing colonisation by $A$ fumigatus and hypersensitivity mechanisms, allied to respiratory function testing, might be considered.

In summary, we have described a sensitive method for the detection of IgG antibodies to Aspergillus. Patients with cystic fibrosis have high IgG antibody titres to Aspergillus that parallel progression of the disease. What contribution if any the fungus makes to pulmonary disease, and what contribution the high IgG antibodies and inflammatory mechanisms make, remain to be established.

\footnotetext{
References

1 Waldman RH, Jurgensen PF, Olsen GN, Ganguly R, Johnson $\mathrm{JE}$. Immune response of the human respiratory tract. Immunoglobulin levels and influenza virus vaccine antibody response. J Immunol 1973;111:38-41.

2 Forsyth KD, Koh L, Lawrence A, Bradley J. Immunoglobulin profile of tracheal aspirate fluid in intubated children. Clin Exp Immunol 1988; 71: 357-61.

3 Wilmott RW, Tyson SL, Matthew DJ. Cystic fibrosis survival rates. Am J Dis Child 1985;139:669-71.

4 Matthews WJ, Williams M, Oliphint B, Geha R, Colten HR. Hypogammaglobulinemia in patients with cystic fibrosis. $N$ Eng $J$ Med 1980;302:245-9.

5 Wheeler WB, Williams M, Matthew WJ, Colten HR. Progres sion of cystic fibrosis lung disease as a function of serum immunoglobulin G levels: a 5-year longitudinal study. J Pediatr 1984;104:695-9.

6 Turner MW, Warner JO, Stokes CR, Norman AP. Immunological studies in cystic fibrosis. Arch Dis Child 1978;53:631-8. 7 Doggett RG, Harrison GM. Pseudomonas aeruginosa: immune status in patients with cystic fibrosis. Infect Immun 1972;6: 628-35.
} 
${ }^{\wedge}$ Hoiby N, Jacobsen L, Jorgensen BA, Lykkegaard E, Wecke B. Pseudomonas acruginosa infection in cystic fibrosis. Occurrence of precipitating antibodies against Pscudomonas aeruginosa in relation to the concentration of sixteen serum proteins and the clinical and radiologic status of the lungs. Acta Paediatr Scand 1974;63:843-8

" Moss RB, Hsu Yao-Pi, Lewiston NJ. I-Clq binding and specific antibodies as indicators of pulmonaiy disease activity in cystic fibrosis. J Pediatr 1981;99:215-22.

10 Auerbach HS, Williams M, Kirkpatrick JA, Colten H. Alternate day prednisolone reduces morbidity and improves pulmonary function in cystic fibrosis. Lancet 1985;ii:686-8.

1 Bardana E, Sobti K, Cianciulli F, Noonan M. Aspergillus antibody in patients with cystic fibrosis. Am J Dis Child 1975;129:1164-7.

12 Schwartz R, Johnstone D, Holsclaw D, Dooley R. Serum precipitins to Aspergillus fumigatus in cystic fibrosis. Am J Dis Child 1970;120:432-3.

13 Galant S, Rucker R, Groncy C, Wells I, Novey H. Incidence of serum antibodies to several Aspergillus species and to Candida albicans in cystic fibrosis. Am Rev Respir Dis 1976;114:325-31.

14 Nelson L, Callerame M. Schwartz R. Aspergillosis and atopy in cystic fibrosis. Am Rev Respir Dis 1979;120:863-73.
15 Shwachman H, Kulczycki L. Long term study of one hundred five patients with cystic fibrosis. Am J Dis Child 1958;96:6-15.

16 Weintzen R, Utz P. The mycoses other than histoplasmosis, In: Kendig E, Chernick V, eds. Disorders of the respiratory tract in children. 4th ed. Philadelphia: Saunders, 1983:732-62.

17 Bardana E. Pulmonary aspergillosis, In: Al-Doory T, Wagner G, eds. Aspergillosis. Springfield: Charles C Thomas, 1985: 43-78.

18 Sobonya R, Taussig L. Quantitative aspects of lung pathology in cystic fibrosis. Am Rev Respir Dis 1986;134:290-5.

$19 \mathrm{Yu} \mathrm{V}$, Muder R, Poorsattar A. Significance of isolation of Aspergillus from the respiratory tract in diagnosis of invasive pulmonary aspergillosis. Am J Med 1986;81:249-54.

20 Gibbons A, McFarlane $\mathrm{H}$, Allan J, Holzel A. Immunity in patients with cystic fibrosis. $\mathrm{Br}$ Med $J$ 1976;i:120-2.

21 Karam G, Griffin F. Invasive pulmonary aspergillosis in nonimmunocompromised, non-neutropenic hosts. Rev Infect Dis 1986;8:357-63.

Correspondence to: Dr K Forsyth, Department of Immunology, Institute of Child Health, 30 Guilford Street, London WC1N 1EH.

Accepted 28 January 1988 